\title{
Utilization of Sitophilus zeamais (Motschulsky) larvae as a dietary supplement for the production of broiler chickens
}

\author{
S. López-Vergé ${ }^{1}$, A. C. Barroeta ${ }^{1}$ J. Riudavets ${ }^{2}$ and J. J. Rodríguez-Jerez ${ }^{3}$ \\ ${ }^{1}$ Servei de Nutrició i Benestar Animal (SNiBA), Departament de Ciència Animal i dels Aliments, Universitat \\ Autònoma de Barcelona, Barcelona, Spain, ${ }^{2}$ IRTA, Entomologia, Cabrils, Spain and ${ }^{3}$ Grupo de Investigación \\ Biorisc-Grisc, Facultat de Veterinària, UAB, Barcelona, Spain
}

Nowadays, the high rate of human population growth and the consequently higher world food supply are general concerns. Moreover, it is completely necessary to meet the demands for food without over-exploiting natural resources.

In addition to the above it is important to seek available and economic feed resources for animal nutrition that are not directly used for human consumption. Focusing on the poultry nutrition, traditional sources of protein are soybean meal and animal meal ${ }^{(1)}$. These feedstuffs are expensive, and are in high demand for many purposes, so insects could be perfectly used as an alternative cheaper protein source for a partial or total replacement in the future ${ }^{(2)}$.

In the literature we found several experiments focusing in insects as feedstuffs. Besides, the interest in insects is growing and research is developing in paralel to the increasing cost of traditional raw materials. Thereby, more information concerning chemical composition of insects, and their availability is needed.

The aim of this study was to test the validity of insects as feedstuff for broiler chickens. On the one hand, the nutritional composition of 3 insect species (Tenebrio molitor, Ephestia kuehniella, and Tribolium confusum) was determined with the purpose to assess their potential use in animal nutrition. In dry matter basis the results obtained in crude protein (ranging from $42.47 \%$ to $58.77 \%$ ) and ether extract (ranging from $24.99 \%$ to $34.13 \%$ ) support the idea that they can indeed be used in animal nutrition.

On the other hand, a feeding trial was conducted in order to compare the effect of adding larvae of insect species Sitophilus zeamais to the diet on the performance parameters. A total of 36 female broiler chickens of Ross 308 strain were randomly allocated to 12 cages ( 3 animals per cage) and cages were randomly distributed in 2 treatments (6 cages per treatment). Animals fed the insect-infested diet had higher final body weight $(P=0.015)$ and higher average daily feed intake $(\mathrm{ADFI}, P=0.015)$ compared to animals fed the untreated (control) diet. Average daily gain (ADG) was found to be slightly higher, although not quite statistically significant $(P=0.083)$. In addition, there were no significant differences $(P>0.05)$ between treatments for feed conversion ratio $(\mathrm{FCR})$ and carcass yield. Furthermore, a microbiological study was also carried out in order to detect pathogens. The results were negative for both Salmonella sp. and Listeria monocytogenes.

These results, led to conclude that insects could be a valid and safe ingredient for their use as broiler chicken feed. Moreover, the recycling role of insects must be considered in early future, mainly because they are able to perform a significant transduction of low amount of nutrients, present in many forms of waste, into a good quality protein as pointed out by several authors ${ }^{(3)}$.

1. Oyegoke OO, Akintola AJ, Fasoranti JO et al. (2006) African Journal of Biotechnology 5, 1799-1802.

2. Ramos-Elorduy J, González EA, Hernández AR et al. (2002) J Econ Entomol 95, 214-220.

3. Okah U \& Onwujiariri E (2012) Journal of Agricultural Technology 8, 471-477. 